\title{
SISTEM PENGELOLAAN SAMPAH DENGAN MEMANFAATKAN SISTEM INFORMASI GEOGRAFIS (SIG)
}

\author{
Fitri Purnama Sari \\ Program Studi Teknik Lingkungan, Universitas Tanjungpura, Pontianak \\ Email: ipitpurnama@yahoo.com
}

\begin{abstract}
ABSTRAK
Semakin meningkat pertumbuhan suatu penduduk setiap tahunnya dapat menyebabkan permasalahan kompleks yang berdampak pada lingkungan. Salah satunya adalah masalah pencemaran lingkungan disebabkan oleh sampah. Tujuan penelitian ini adalah mengetahui besarnya volume sampah yang dihasilkan TPS Pasar Kemuning, mengetahui sistem pengelolaan sampah seperti rute pengangkutan sampah dari TPS Pasar Kemuning menuju TPA Batu Layang, serta memperoleh alternatif rute pengangkutan dengan menggunakan Sistem Informasi Geografis (SIG).

Aspek yang menyangkut sistem pengelolaan sampah yaitu sumber penghasil sampah, pengumpulan sampah sementara (TPS), pengangkutan sampah dan pembuangan akhir sampah. Penelitian ini, dilakukan analisa untuk memberikan penilaian terhadap rute yang ada dengan menggunakan metode pembobotan/perangkingan. Untuk mendapatkaan rute terbaik dari parameter yang digunakan yaitu parameter berdasarkan jarak jalan dan parameter berdasarkan waktu tempuh didapatkan dari volume lalu lintas, lebar jalan, kondisi jalan, serta waktu.

Untuk mengoperasikan SIG pada skripsi ini digunakan alat bantu berupa software ArcGis agar dapat memberikan suatu rute terbaik dari alternatif pemilihan rute. Dari hasil analisa didapatkan volume timbulan sampah TPS Pasar Kemuning per harinya adalah 58,339 $\mathrm{m}^{3} /$ hari dan jumlah armada kendaraan pengangkutan sampah TPS Pasar Kemuning 2 (dua) buah Container dengan ritasi 3 (tiga) rit /hari, dan 2 (dua) buah Dump Truck dengan ritasi 4 (empat) rit /hari. Hasil analisa penilaian rute alternatif dengan menggunakan SIG diperoleh rute terbaik yang dapat dilihat berdasarkan total bobot terbesar yaitu pada rute 2 (dua) dengan jarak tempuh $\pm 24 \mathrm{Km}$ dari TPS Pasar Kemuning menuju TPA Batu Layang.
\end{abstract}

Kata kunci: Pengelolaan Sampah, TPS, SIG

\begin{abstract}
Growth increasing of the population every year can lead to complex problems that impact on the environment. One of the problem is environmental pollution caused by waste. The purpose of this study was to determine the volume of waste generated by Kemuning Market's dumpster, to know the system of waste management such as waste transportation route from Kemuning Market's dumpster to Batu Layang landfill, and obtaining alternative transportation route using Geographic Information Systems (GIS).

Aspects related to the waste management system are the source of the waste, dumpster, waste transportation and disposal of waste. This study, conducted the analysis to provide an assessment of the existing route by using weighting or rangking. Parameters used to get the best route are parameter based on distance and parameter based on travel time obtained by traffic volume, road width, and time. This thesis used ArcGIS software to operate GIS to provide the best route of alternate route selection.

Result of the analysis found the volume of solid waste per day Kemuning Market TPS are 58,339 m3/day and amount waste vehicles of Kemuning Market's dumpster are 2 (two) units Container with 3 (tri) trips / day, and 2 (two) Dump Truck with 4 (four) trips / day. The results of the analysis is an alternate route assessment using GIS obtained the best route that can be seen by the largest total of weight is on route 2 (two) with the distance $\pm 24 \mathrm{~km}$ from Kemuning Market's dumpster to Batu Layang landfill.
\end{abstract}

Keywords: Waste Management, Dumpster, SIG 


\section{Pendahuluan}

Perkembangan suatu kawasan selalu diikuti dengan jumlah Penduduk yang semakin meningkat sehingga akan menimbulkan suatu dampak yang disebabkan karena adanya kecenderungan sampah yang meningkat pula. Permasalahan lingkungan yang umumnya sering terjadi di lingkungan perkotaan adalah pengelolaan sampah yang kurang baik. Untuk mencapai suatu sistem pengelolaan sampah yang baik salah satu fasilitas yang menunjang antara lain adalah perlu dilakukan penanganan yang serius, karena pengelolaan sampah bukan hal yang mudah disamping itu memerlukan dana yang tidak sedikit (Damanhuri,2004).

Pengelolaan sampah menyangkut beberapa aspek seperti tempat Pengumpulan Sampah Sementara (TPS), pengelolaan manejemen, armada pengangkut sampah yang tersedia serta kurangnya kesadaran Masyarakat dalam menjaga kebersihan lingkungan. Pada Tempat Pengumpulan Sementara (TPS) Pasar Kemuning yang terletak di jalan Prof. M Yamin penanganan sampahnya pada saat ini masih menggunakan paradigma lama, yaitu sampah yang telah terkumpul pada bak penampungan TPS kemudian diangkut ke TPA. Menurut observasi lapangan yang telah dilakukan, saat ini kondisi tempat pengumpulan sampah sementara (TPS) yang telah tersedia sudah cukup untuk menampung sampah yang ada, akan tetapi kurangnya kesadaran masyarakat sekitar untuk membuang sampahnya tepat pada bak sampah yang telah disediakan oleh Dinas Kebersihan dan Pertamanan Kota Pontianak dan tidak mematuhi peraturan yang telah ditetapkan oleh Pemerintah No. 5 tahun 2006 agar membuang sampah pada jam 6 sore -6 pagi.

Sampah adalah istilah umum yang sering digunakan untuk menyatakan limbah padat. Pembagian sampah dapat dilakukan dengan berbagai cara tergantung dari kondisi oleh kebijakan wilayah setempat. Ada yang berdasarkan sumber penghasilannya, ada yang berdasarkan komposisinya, dan ada pula yang berdasarkan cara penanganannya. Selain itu ada pula pembagian berdasarkan istilah teknis dan berdasarkan pada sumber yang ditimbulkannya (Alfiandra, 2010)

Sistem Informasi Geografis (SIG) dijadikan sebagai alat bantu yang digunakan untuk pemetaan dan analisa terhadap banyak aktivitas diatas permukaan bumi. Penggunaan SIG pada saat ini bukan hal yang baru lagi tetapi sudah banyak digunakan dalam berbagai bidang. Container dan Dump Truck merupakan salah satu alat transportasi pengangkut sampah yang sebagian besar digunakan untuk melayani TPS di Kota Pontianak. Salah satu bidang yang dapat menyelesaikan masalah tersebut adalah membuat rute pengangkutan sampah dari TPS Pasar Kemuning menuju TPA Batu Layang dengan menggunakan Sistem Informasi Geografis (SIG). Sistem tersebut dapat menyajikan data secara akurat, cepat, murah dan dapat melakukan analisis dari data spasial maupun data atributnya.

Dengan berkembangnya teknologi digital yang sangat besar peranannya dalam perkembangan penggunaan Sistem Informasi Geografis (SIG) dan dalam berbagai bidang yang memanfaatkan teknologi komputer untuk pengelolaan dan pengambilan keputusannya, maka bertolak dari permasalahan tersebut Penulis tertarik untuk melakukan penelitian sampai sejauh mana Sistem Informasi Geografis (SIG) dapat memberikan informasi tentang rute terbaik pengangkutan sampah dari TPS Pasar Kemuning menuju TPA Batu Layang di Kota Pontianak.

Berdasarkan permasalahan di atas, maka muncullah gagasan yang bertujuan untuk mengetahui volume sampah yang dihasilkan tps (tempat pengumpulan sampah) pasar kemuning, mengetahui sistem pengelolaan sampah seperti rute pengangkutan sampah dari tps pasar kemuning menuju tpa batu layang, waktu pengangkutan, jumlah armada pengangkutan yang digunakan serta jumlah rit/hari dalam proses pengangkutan, memperoleh alternatif rute pengangkutan menggunakan sistem informasi geografis (sig).

\section{Metode Penelitian}

Penelitian yang dilakukan adalah survey langsung ke lokasi studi atau lapangan dan mengumpulkan data, baik itu berupa data primer maupun data sekunder untuk mendapatkan hasil yang diinginkan dalam penelitian ini. Tahapan-tahapan dari penelitian yang dilakukan adalah analisis pengelolaan sampah. Analisis pengelolaan sampah dilakukan untuk mengetahui volume total sampah yang dihasilkan dari TPS Pasar Kemuning, mengetahui Tempat Pengumpulan Sementara, mengetahui volume sampah, mengakses peta digital peta digital yang diakses yaitu peta digital jaringan jalan Kota 
Pontianak, membuat basis data atribut jalan basis data atribut jalan dibuat dengan perangkat lunak ArcMap berisi data panjang jalan, fungsi jalan, lebar jalan, kondisi jalan, waktu, dan volume lalu lintas basis data ini kemudian diintegrasikan dengan peta digital, penggabungan data spasial dan data atribut agar data spasial dan data atribut menjadi satu kesatuan maka dilakukan proses penggabungan melalui identifier yang unik, membuat program tampilan rute pengangkutan sampah supaya informasi rute pengangkutan sampah dapat ditampilkan lebih menarik lagi seperti legenda peta, arah utara peta, skala peta program tampilan rute dibuat dengan perangkat lunak ArcMap analisa pemilihan rute terbaik analisa pemilihan rute terbaik ini dilakukan perankingan berdasarkan bobot kriteria rute.

\section{Hasil dan Pembahasan}

Sumber penghasil sampah di TPS Pasar Kemuning berasal dari pertokoan, aktifitas pasar, dan juga pemukiman masyarakat yang berada di daerah lokasi dan sekitarnya. Pengangkutan sampah yang dilakukan saat ini diatur dengan sistem lokasi, dengan pengertian bahwa setiap unit sarana angkutan yang dioperasikan telah ditetapkan lokasi pelayanannya pada satu atau beberapa lokasi secara tetap dan merupakan lokasi tugas yang menjadi tanggung jawab masing-masing sarana angkutan sampah tersebut. Pengangkutan sampah di TPS Pasar Kemuning dengan menggunakan Truck/Dump Truck, sedangkan container diangkut dengan Arm Roll Truck. Pengangkutan sampah dengan menggunakan Dump Truck dan Arm Roll Truck dilakukan secara rutin setiap hari dan masingmasing sarana pengangkutan sampah yang dioperasikan adalah 2 (dua) rit/hari untuk angkutan Dump Truck, 2 (dua) rit/hari untuk angkutan Arm Roll Truck. Pengangkutan sampah dari TPS menuju TPA dilakukan sebanyak 3 (tiga) periode yaitu pada jam 05.00 pagi, jam 10.00 pagi, dan sore hari pada jam 17.00. Jarak tempuh untuk sampai ketempat pembuangan akhir (TPA) kurang lebih \pm 23 $\mathrm{km}$. Karena jalur yang dilalui masih melalui jalur yang padat kendaraan.

A. Analisa Volume Sampah

Penentuan analisa volume sampah yang dihasilkan setiap harinya di TPS Pasar Kemuning tergantung dari banyaknya pembuangan sampah dari pertokoan, ruko, perumahan-perumahan masyarakat, dan aktifitas Pasar Kemuning yang berada disekitar TPS tersebut.

Rumus yang digunakan untuk perhitungan volume sampah adalah sebagai berikut :

Volume sampah $(\mathrm{V})=p \times I \times t$

Keterangan :

$$
\begin{aligned}
& p=\text { Panjang bak sampah }(\mathrm{m}) \\
& I=\text { Lebar bak sampah }(\mathrm{m}) \\
& t=\text { Tinggi bak sampah }(\mathrm{m}) \\
& \mathrm{V}=\operatorname{Volume} \operatorname{sampah}\left(\mathrm{m}^{3} / \text { hari }\right)
\end{aligned}
$$

Adapun perhitungan volume sampah per hari yang dihasilkan pada TPS Pasar Kemuning dapat dihitung dengan menggunakan rumus pada persamaan (1).

- Volume sampah pada bak sampah per hari

$$
\begin{aligned}
& =7 \mathrm{~m} \times 2 \mathrm{~m} \times 1,59 \mathrm{~m} \\
& =22,26 \mathrm{~m}^{3} / \text { hari } \\
& =6,4 \mathrm{~m} \times 1,9 \mathrm{~m} \times 1,2 \mathrm{~m} \\
& =14,592 \mathrm{~m}^{3} / \text { hari } \\
& =6,92 \mathrm{~m} \times 3,45 \mathrm{~m} \times 0,9 \mathrm{~m} \\
& =21,487 \mathrm{~m}^{3} / \text { hari }
\end{aligned}
$$

- Volume sampah pada bak Container per hari

- Volume sampah pada sisa bak sampah per hari

- Volume total sampah per hari = Volume bak sampah + Volume bak Container +Volume sisa bak sampah

$$
\begin{aligned}
& =22,26+14,592+21,487 \\
& =58,339 \mathrm{~m}^{3} / \text { hari }
\end{aligned}
$$

Jadi dapat diketahui jumlah volume sampah perhari yang dihasilkan oleh TPS Pasar Kemuning adalah sebanyak $58,339 \mathrm{~m}^{3} /$ hari. 
B. Kebutuhan container dan dump truck di TPS $6 \mathrm{~m}^{3}$ Jumlah sampah bak Container $=14,592 \mathrm{~m}^{3} /$ hari

Maka jumlah alat angkut yang dibutuhkan menggunakan rumus :

$$
\begin{aligned}
\text { Container } & =\frac{\text { Jumlah sampah bak container }}{\text { Volume angkutan container }} \\
& =\frac{14,592 \mathrm{~m}^{3} / \text { hari }}{6 \mathrm{~m}^{3}}=2,432 \text { hari } \approx 3 \text { buah } / \text { hari }
\end{aligned}
$$

C. Dump truck kapasitas angkutan sebesar $11,13 \mathrm{~m}^{3}$

Untuk jenis alat angkut dump truck ini volume sebenarnya adalah sebesar $7,42 \mathrm{~m}^{3}$, tetapi angkutan ini sudah dimodifikasi yang terbuat dari kayu papan untuk menambah jumlah volume muatan sampah sehingga volume bertambah menjadi $11,13 \mathrm{~m}^{3}$.

Jumlah sampah Dump Truck $=43,747 \mathrm{~m}^{3} /$ hari

Maka jumlah alat angkut yang dibutuhkan menggunakan rumus :

$$
\begin{aligned}
\text { Dump Truck } & =\frac{\text { Jumlah sampah dump truck }}{\text { Volume angkutan Dump Truck }} \\
& =\frac{43,747 \mathrm{~m}^{3} / \text { hari }}{11,13 \mathrm{~m}^{3}}=3,93 \text { hari } \approx 4 \text { buah } / \text { hari }
\end{aligned}
$$

D. Rencana Alternatif Rute Jalan Yang Akan Dipilih

\begin{tabular}{|c|c|}
\hline Alternatif Rute Pengangkutan & Nama Jalan \\
\hline Rute 1 & $\begin{array}{ll}\text { 1. } & \text { Jl. Prof M Yamin } \\
\text { 2. } & \text { Jl. Sutan Syahrir } \\
\text { 3. } & \text { Jl. Sultan Abdurrahman } \\
\text { 4. Jl. A Yani } \\
\text { 5. Jl. Veteran } \\
\text { 6. Jl. Pahlawan } \\
\text { 7. } \\
\text { 8. Sultan Hamid II } \\
\text { 9. Jl.28 Oktober } \\
\text { 10. Jl. Kebangkitan Nasional Dalam }\end{array}$ \\
\hline Rute 2 & $\begin{array}{ll}\text { 1. } & \text { Jl. Prof M Yamin } \\
\text { 2. } & \text { Jl. Dr Sutomo } \\
\text { 3. Jl. Pangeran Natakusuma } \\
\text { 4. Jl. Alianyang } \\
\text { 5. Jl. Wahid Hasyim } \\
\text { 6. Jl. Johar } \\
\text { 7. Jl. Urip Sumoharjo } \\
\text { 8. Jl. Jendral Sudirman } \\
\text { 9. Jl. Tanjung Pura } \\
\text { 10. Jl. Sultan Hamid II } \\
\text { 11. Jl. 28 Oktober } \\
\text { 12. Jl. Budi Utomo } \\
\text { 13.Jl. Kebangkitan Nasional Dalam }\end{array}$ \\
\hline
\end{tabular}

Alternatif rute jalan untuk pengangkutan sampah TPS Pasar Kemuning menuju TPA Batu Layang dapat dilihat pada Tabel 1.

Tabel 1: Alternatif Rute Pengangkutan 


\begin{tabular}{|l|l|}
\hline & 1. Jl. Prof M Yamin \\
& 2. Jl. Tani Makmur \\
3. Jl. Wonobaru \\
4. J. Purnama \\
Rute 3 & 5. J. Sutoyo \\
& 6. J. A Yani \\
7. J. Arteri Supadio \\
8. Jl. Trans Kalimantan \\
9. J. Ya'm Sabran \\
10. J. 28 Oktober \\
11. Jl. Budi Utomo \\
12. Jl. Kebangkitan Nasional Dalam
\end{tabular}

Untuk mendapatkan rute jalan terbaik dari pemilihan alternatif jalan yang telah ditentukan, parameter-parameter yang digunakan antara lain adalah berdasarkan jarak jalan dan waktu tempuh.

a. Parameter Berdasarkan Jarak Jalan

Dalam penulisan skripsi ini jarak sangat penting karena dari jarak tersebut kita dapat mengetahui berapa panjang rute jalan yang akan dilalui oleh alat angkut sampah dari TPS Pasar Kemuning menuju TPA Batu Layang. Jarak adalah penjumlahan dari setiap jarak jalan yang akan dilalui. Dari 3 rute alternatif tersebut akan menghasilkan rute jalan terpendek. Adapun jarak ke 3 alternatif rute dapat dilihat pada Tabel $\mathbf{2}$.

Tabel 2: Rute 1,2 dan 3 Berdasarkan Jarak Jalan

\begin{tabular}{|c|c|}
\hline Alternatif Rute Jalan & Jarak (Km) \\
\hline 1 & $22,92 \mathrm{Km}$ \\
\hline 2 & $23,50 \mathrm{Km}$ \\
\hline 3 & $38,30 \mathrm{Km}$ \\
\hline
\end{tabular}

Berikut ini adalah Gambar 1 merupakan tampilan layout rute yang ditampilkan dari software ArcGis dengan menghubungkan TPS Pasar Kemuning menuju TPA Batu Layang

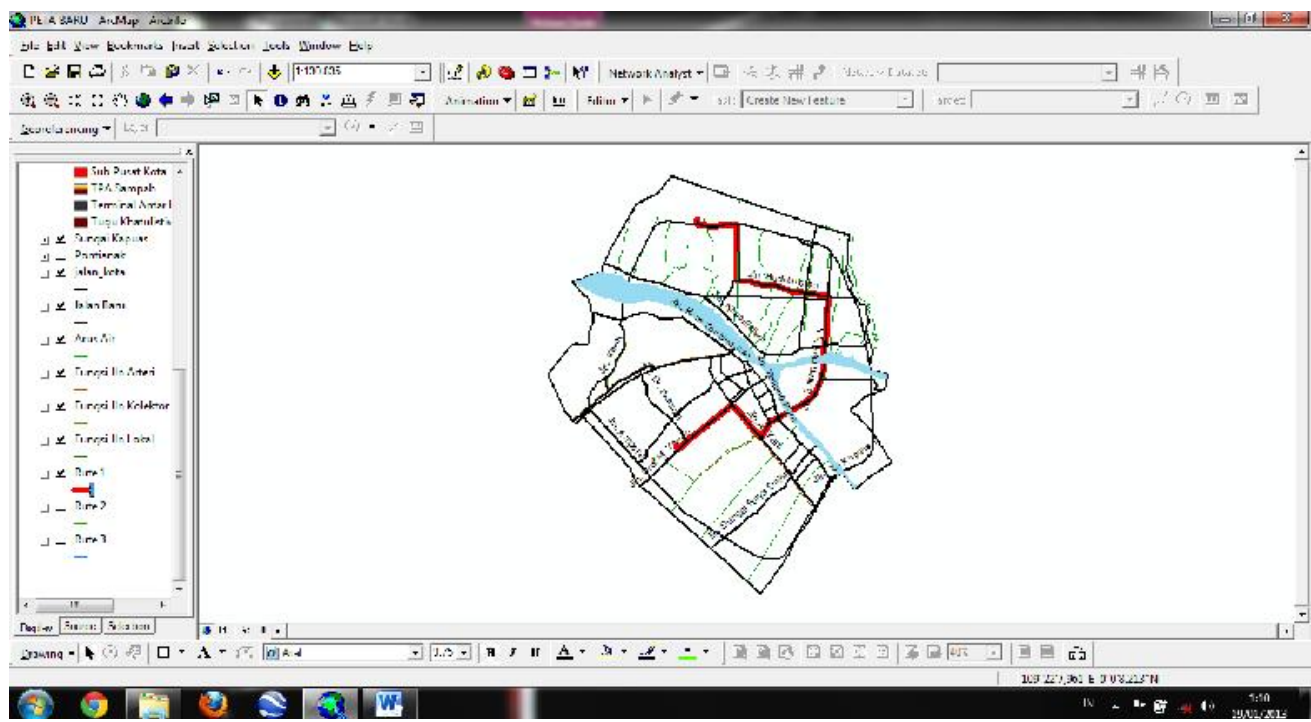

a. Layout Rute 1 


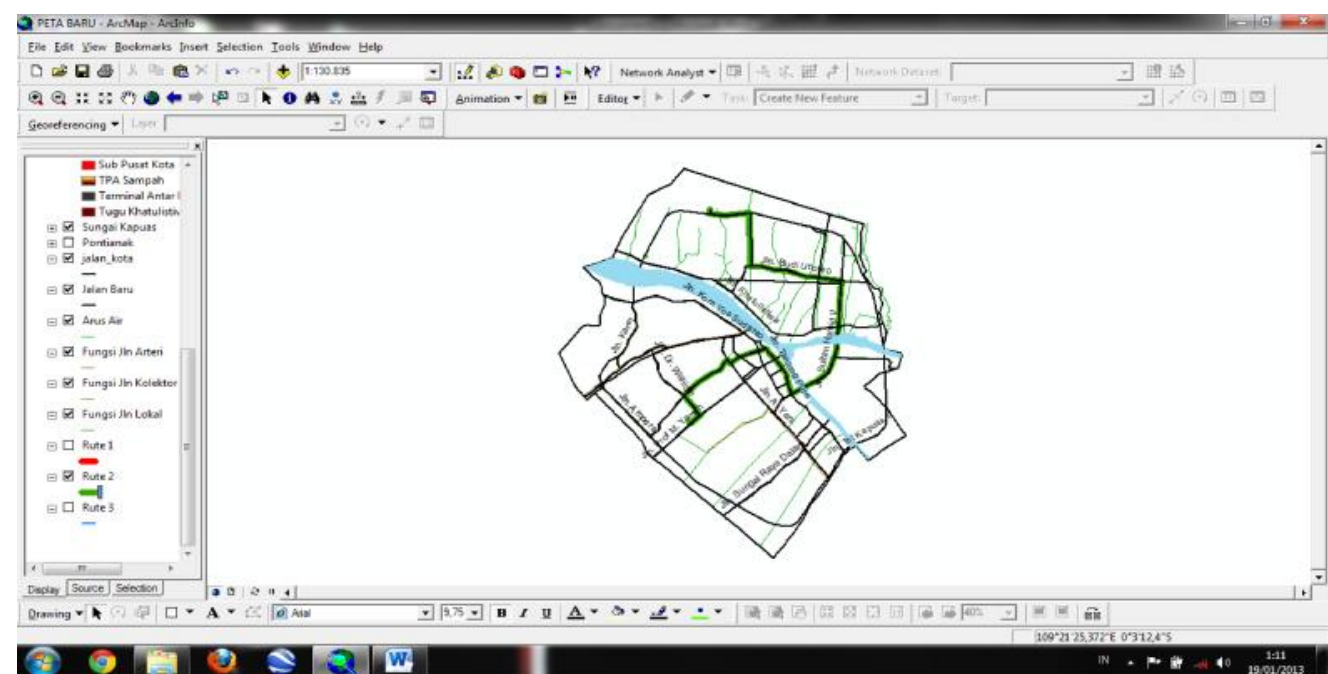

b. Layout Rute 2

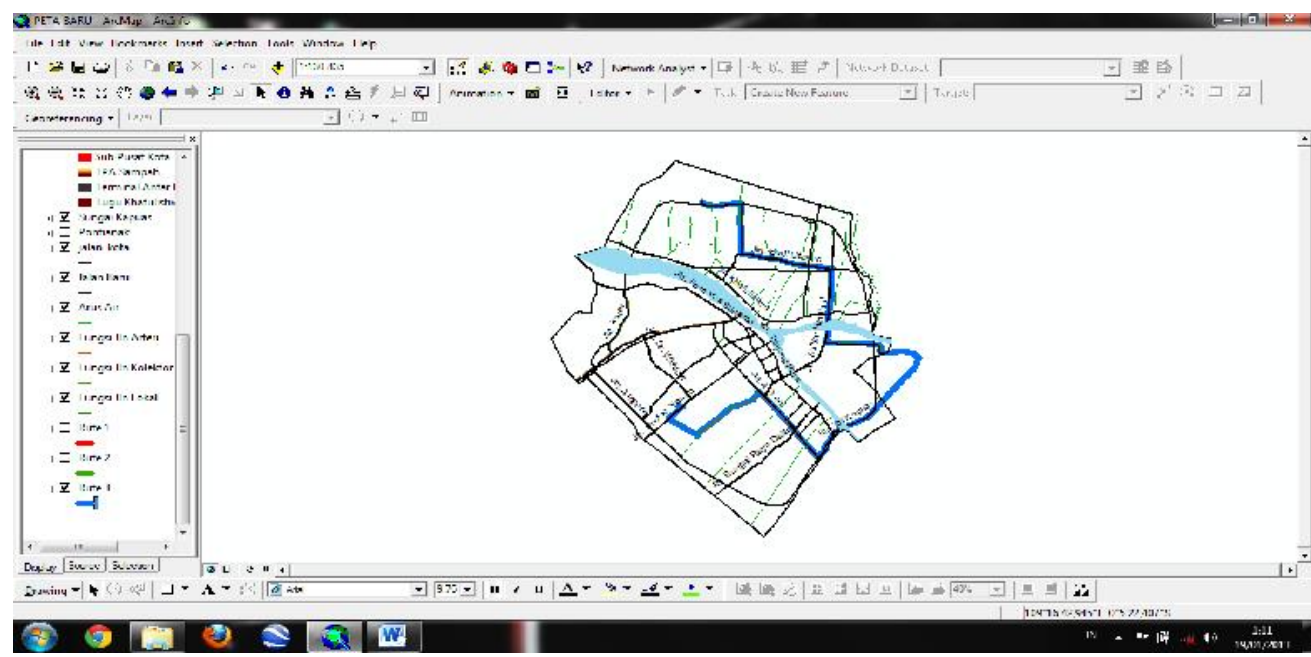

c. Layout Rute 3

Gambar 1: Tampilan Layout Rute 1,2,3 menggunakan software ArcGis

Jadi, setelah mendapatkan jarak tempuh dari ketiga rute tersebut diperoleh rute dengan jarak terpendek adalah rute 1 (satu) dengan total jarak tempuh $\pm 23 \mathrm{Km}$ dari TPS Pasar Kemuning menuju TPA Batu Layang. Jarak tempuh dari setiap rute didapatkan dari penjumlahan jarak setiap jalan yang akan dilalui.

b. Parameter Berdasarkan Waktu Tempuh

Parameter berdasarkan waktu tempuh pengangkutan sampah dari TPS Pasar Kemuning menuju TPA Batu Layang ditentukan dengan perangkingan untuk menghasilkan data atribut bobot dari parameter volume lalu lintas, lebar jalan, kondisi jalan, serta waktu.

Pembobotan yang telah didapatkan dari perangkingan tersebut akan dibandingkan terhadap aplikasi software ArcGis. Nilai pembobotan dari perangkingan masing-masing parameter dapat dilihat pada Tabel 3. 
Tabel 3 : Nilai Bobot Dari Hasil Perangkingan

\begin{tabular}{|c|c|c|c|}
\hline No & Parameter & Rangking & Skor \\
\hline \multirow{2}{*}{1} & \multirow{2}{*}{ Waktu } & $0 \leq 1$ & 2 \\
\hline & & $1 \leq 2$ & 1 \\
\hline \multirow{3}{*}{2} & Beton Aspal (Baik) & & 3 \\
\hline & Aspal (Kurang Baik) & & 2 \\
\hline & Tanah Dengan Pekerasan (Buruk) & & 1 \\
\hline \multirow{6}{*}{3} & \multirow{6}{*}{ Lebar Jalan } & $0 \leq 4$ & 1 \\
\hline & & $4 \leq 8$ & 2 \\
\hline & & $8 \leq 12$ & 3 \\
\hline & & $12 \leq 16$ & 4 \\
\hline & & $16 \leq 20$ & 5 \\
\hline & & $20 \leq 24$ & 6 \\
\hline \multirow{8}{*}{4} & \multirow{8}{*}{ Volume Lalu Lintas } & $0 \leq 100$ & 8 \\
\hline & & $100 \leq 200$ & 7 \\
\hline & & $200 \leq 300$ & 6 \\
\hline & & $300 \leq 400$ & 5 \\
\hline & & $400 \leq 500$ & 4 \\
\hline & & $500 \leq 600$ & 3 \\
\hline & & $600 \leq 700$ & 2 \\
\hline & & $700 \leq 800$ & 1 \\
\hline
\end{tabular}

Nilai bobot yang telah didapatkan untuk parameter ini semakin besar nilai yang didapatkan maka semakin baik kapasitas jalan tersebut.

Berikut ini adalah tampilan dari data atribut Tabel rute 1, 2 dan rute 3 berdasarkan waktu tempuh yang telah dibobotkan. Dapat dilihat pada Tabel 4, 5 dan 6.

Tabel 4: Data Atribut Rute 1

\begin{tabular}{|c|c|c|c|c|c|c|c|c|c|c|c|}
\hline$N_{0}$ & $\begin{array}{l}\text { Nama } \\
\text { Jalan }\end{array}$ & $\begin{array}{c}\text { Lebar } \\
\text { Jalan (m) }\end{array}$ & $\begin{array}{l}\text { Bobyt } \\
\text { Jalan }\end{array}$ & $\begin{array}{c}\text { Fungsi } \\
\text { Jalan }\end{array}$ & $\begin{array}{c}\text { Kondisi } \\
\text { Jalan }\end{array}$ & $\begin{array}{c}\text { Bobot } \\
\text { Kendisi Jalan }\end{array}$ & \begin{tabular}{|c|} 
Volume \\
Lalu Lintas \\
\end{tabular} & $\begin{array}{l}\text { Bobot Volume } \\
\text { Lalu Lintas }\end{array}$ & $\begin{array}{l}\text { Waktu } \\
\text { (Jam) }\end{array}$ & $\begin{array}{l}\text { Bobot } \\
\text { raktu }\end{array}$ & Total Bobot \\
\hline 1 & II. Prof M Yarrin & 12 & 3 & Arteri & Beton, Aspal (Baik) & 3 & 143 & 7 & 1 & 2 & 15 \\
\hline 2 & II. Sutan Syahrr & 9 & 3 & Arteri & Beton, Aspal (Bailk) & 3 & 514 & 3 & 1 & 2 & 11 \\
\hline 3 & II. Sutan Abdurrahman & 12 & 3 & Arteri & Beton, Aspal (Baik) & 3 & 714 & 1 & 1 & 2 & 9 \\
\hline 4 & II.A Yani & 18 & 5 & Arteri & Beton, Aspal (Bail) & 3 & 612 & 2 & 1 & 2 & 12 \\
\hline 5 & II. Veteran & 16 & 4 & Arteri & Beton, Aspal (Baik) & 3 & 53) & 3 & 1 & 2 & 12 \\
\hline 6 & II. Pahlawan & 22 & 6 & Arteri & Beton, Aspal (Baik) & 3 & 479 & 4 & 1 & 2 & 15 \\
\hline$?$ & II. Suitan Hamic II & 8 & 2 & Arteri & Beton, Aspal (Baik) & 3 & 307 & 5 & 1 & 2 & 12 \\
\hline 8 & II. 28 Oktober & 12 & 3 & Arteri & Aspal (Kurang Baik) & 2 & 177 & 7 & 1 & 2 & 14 \\
\hline 9 & I. Bud: Utcmo & 6 & 2 & Lokal & Beton, Aspal (Baik) & 3 & 175 & 7 & 1 & 2 & 14 \\
\hline 10 & II. Kebanghitan Nesicral Dalan & 5 & 2 & Lokal & Tanah Perkerasan (Buruk) & 1 & 12) & 7 & 1 & 2 & 12 \\
\hline \multicolumn{3}{|c|}{ Total Penjumlahan Masing-Masing Bobot } & 33 & & 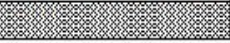 & 27 & 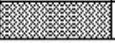 & 46 & & 20 & 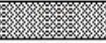 \\
\hline \multicolumn{11}{|c|}{ IOTAL KESELURUHAN BOBOT } & 126 \\
\hline
\end{tabular}

Tabel 5: Data Atribut Rute 2

\begin{tabular}{|c|c|c|c|c|c|c|c|c|c|c|c|}
\hline No & $\begin{array}{l}\text { Nama } \\
\text { Jelan }\end{array}$ & \begin{tabular}{|c|} 
| ehar \\
Jalan $[\mathrm{m})$
\end{tabular} & $\begin{array}{l}\text { Rohont } \\
\text { Jalan }\end{array}$ & $\begin{array}{l}\text { Fungsi } \\
\text { Jalan }\end{array}$ & $\begin{array}{l}\text { Kondisi } \\
\text { Jalen }\end{array}$ & $\begin{array}{c}\text { Rohot } \\
\text { Kondisi Jalan } \\
\end{array}$ & $\begin{array}{c}\text { Volume } \\
\text { Lalu Lintas }\end{array}$ & $\begin{array}{c}\text { Rohnot Volume } \\
\text { Lalu Lintas }\end{array}$ & $\begin{array}{l}\text { Waktu } \\
\text { (Jam) }\end{array}$ & $\begin{array}{l}\text { Rohnt } \\
\text { waltu }\end{array}$ & Total Bobot \\
\hline 1 & 1.. Prof M Yamin & 12 & 3 & Arteri & Eeton, Aspal (Baik) & 3 & 143 & 7 & 1 & 2 & 15 \\
\hline 2 & J.. Dr Sutoro & 6 & 2 & Lokal & Eeton, Aspal (Ba ik) & 3 & 549 & 3 & 1 & 2 & 10 \\
\hline 3 & J.. Pargeran Natakusıma & 8 & 2 & Arteri & Eeton, Aspal (Baik) & 3 & 559 & a & 1 & 2 & 10 \\
\hline 4 & J._. Alianyang & 8 & 2 & Kolektor & Eeton, Aspal (Baik) & 3 & 553 & 3 & 1 & 2 & 10 \\
\hline 5 & J.. Wahid Hasyim & 11 & 3 & Arteri & Eeton, Aspal (Baik) & 3 & $\varepsilon \subseteq$ & $\varepsilon$ & 1 & 2 & 16 \\
\hline 6 & Ј... Јоาar & 8 & 2 & Arteri & Eeton, Aspal (Baik) & 3 & 559 & 3 & 1 & 2 & 10 \\
\hline 7 & J.. Urip Surcharjo & 8 & 3 & Arteri & Eeton, Aspal (Baik) & 3 & 555 & 3 & 1 & 2 & 11 \\
\hline 8 & I.. Jendral Sudirman & 9 & 3 & Arteri & Eeton, Aspal (Baik) & 2 & 579 & $\mathrm{a}$ & 1 & 2 & 10 \\
\hline 9 & J._. Tanjung P.ra & 18 & 5 & Arteri & Eeton, Aspäl (Baik) & 3 & 541 & 2 & 1 & 2 & 12 \\
\hline 10 & J._ Sulter Hamid II & 8 & 2 & Arteri & Eeton, Aspal (Baik) & 3 & 309 & 5 & 1 & 2 & 12 \\
\hline 11 & J.. 28 Oktober & 12 & 3 & Arteri & Aspal IKuraาg Baik) & 2 & 177 & 7 & 2 & 1 & 13 \\
\hline 12 & J.. Buci Utoro & 6 & 2 & Lokal & Aspal |Kuraาg Baik) & 2 & 175 & 7 & 2 & 1 & 12 \\
\hline 13 & J.. Kebang<itaา $₫ \bar{c}$ sional Dalam & 5 & 2 & Lokal & Tanah Perkerasar IEur.sk & 1 & 120 & 7 & 2 & 1 & 11 \\
\hline \multicolumn{3}{|c|}{ Total Penjumlahan Masing-Masing Bobot } & 34 & \multirow{2}{*}{\multicolumn{2}{|c|}{ TOTAL KESEURUHAN BOBOT }} & 34 & 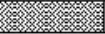 & 51 & 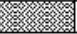 & 23 & 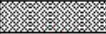 \\
\hline & & & & & & & & & & & 152 \\
\hline
\end{tabular}


Tabel 6: Data Atribut Rute 3

\begin{tabular}{|c|c|c|c|c|c|c|c|c|c|c|c|}
\hline No & $\begin{array}{r}\text { Nama } \\
\text { Jalan }\end{array}$ & \begin{tabular}{|c|} 
Ifhar \\
Jalan (m)
\end{tabular} & $\begin{array}{r}\text { Rohat } \\
\text { Jalan }\end{array}$ & $\begin{array}{l}\text { Fungei } \\
\text { Jalan }\end{array}$ & $\begin{array}{c}\text { Kondisi } \\
\text { Jalan }\end{array}$ & $\begin{array}{c}\text { Rohnot } \\
\text { Kondisi Jalan }\end{array}$ & $\begin{array}{c}\text { Volume } \\
\text { Lalu Lintas }\end{array}$ & $\begin{array}{c}\text { Enhont Volume } \\
\text { Lalu Lintas }\end{array}$ & $\begin{array}{l}\text { Waktu } \\
\text { (Jam) }\end{array}$ & $\begin{array}{l}\text { Rnhot } \\
\text { waktu }\end{array}$ & Total Bobot \\
\hline 1 & Jl. Prof M Yamin & 12 & 3 & Atteri & Baton, Aspal (Baik) & 3 & 200 & 7 & 1 & 2 & 15 \\
\hline 2 & IL. Tani Maknur & 5 & 2 & Lokal & Beton, Aspal (Baik) & 3 & 549 & 3 & 1 & 2 & 10 \\
\hline 3 & JL. Wonobaru & 7 & 2 & Lokal & Aspal (Kurang Baik) & 2 & 559 & 3 & 1 & 2 & 9 \\
\hline 4 & IL. Purnama & 9 & 3 & Atteri & Baton, Aspal (Baik) & 3 & 711 & 1 & 1 & 2 & 9 \\
\hline 5 & JL. S.tcyo & 16 & 4 & Atteri & Baton, Aspal (Baik) & 3 & 309 & 5 & 1 & 2 & 14 \\
\hline 6 & JL. A Yanı & 18 & $b$ & Ateri & Beton, Aspal (Ba $\mid \mathrm{k})$ & 3 & yל & 3 & 1 & 2 & 13 \\
\hline 7 & JL. As let i Supadiu & 18 & 5 & A:tei $i$ & Belurl, Aypal (Byik) & $s$ & 556 & $\mathrm{~s}$ & 1 & 2 & 15 \\
\hline 8 & JL. Trans Kolimantan & 7 & 2 & Kolcktor & Bzton, Aspol (Baik) & 3 & 570 & 3 & 1 & 2 & 10 \\
\hline 10 & IL. Ya'm Sabran & 7 & 2 & Lokal & Baton, Aspal (Ba ik) & 3 & 641 & 2 & 1 & 2 & 9 \\
\hline 11 & IL. S.ltan Hamid II & 8 & 2 & Ateri & Baton, Aspal (Baik) & 3 & 425 & 4 & 1 & 2 & 11 \\
\hline 12 & IL. 28 Oktober & 12 & 3 & Atteri & Aspal (Kurang Baik) & 2 & 177 & 7 & 2 & 1 & 13 \\
\hline 13 & IL. Budi Utomo & 6 & 2 & Lokal & Aspal (Kurang Baik) & 2 & 175 & 7 & 2 & 1 & 12 \\
\hline 14 & IL. Kebangkitan Nasional Dalam & 5 & 2 & Lokal & Tanaר Perkerasan (Eur $J k$ ) & 1 & 120 & 7 & 2 & 1 & 11 \\
\hline \multicolumn{3}{|c|}{ Total Perjumlchan Masing-Vasing Bobot } & 37 & & $\begin{array}{l}x_{2} \\
2 x\end{array}$ & 34 & $x$ & 55 & 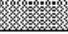 & 23 & 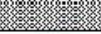 \\
\hline \multicolumn{6}{|c|}{ TOTAL KESELUUUHAN BOBOT } & & & & & & 149 \\
\hline
\end{tabular}

Setelah mendapatkan nilai pembobotan keseluruhan (seperti jumlah bobot lebar jalan, jumlah bobot kondisi jalan, jumlah bobot volume lalu lintas, jumlah bobot waktu tempuh) dengan menggunakan alat bantu berupa software ArcGIS diperoleh rute jalan terbaik yaitu rute 2 (dua) dengan jumlah total bobot berdasarkan waktu tempuh lebih besar dibanding rute yang lain yaitu 152.

Dalam melakukan pengukuran waktu tempuh dilakukan survey langsung dilapangan sebagai data validasi, dari hasil pengukuran yang telah didapat waktu tempuh yang tercepat adalah rute 2 (dua) dan akan dibandingkan dengan hasil model berdasarkan waktu tempuh alternatif yang telah dibuat dengan menggunakan ArcGis. Berikut tabel total waktu tempuh yang merupakan hasil validasi berdasarkan survey pengukuran di lapangan. Dapat dilihat pada Tabel 7, 8, 9 .

Tabel 7 : Total Waktu Tempuh Rute 1

\begin{tabular}{|c|c|c|c|c|c|c|}
\hline \multirow{13}{*}{ Rute 1} & \multirow{3}{*}{ Nama Jalan } & \multirow{3}{*}{$\begin{array}{c}\text { Jarak Jalan } \\
(\mathrm{Km})\end{array}$} & \multicolumn{3}{|c|}{ Waktu (menit/hari) } & Total Waktu \\
\hline & & & $05.00 \mathrm{WTB}$ & $10.00 \mathrm{WTB}$ & \multirow{2}{*}{$\frac{17.00 \mathrm{WIS}}{\left(\mathrm{t}_{3}\right)}$} & \multirow{2}{*}{ (Jam/hari) } \\
\hline & & & $\left(t_{1}\right)$ & $\left(t_{2}\right)$ & & \\
\hline & Л. Prof M Yamin & 0,21 & 0,28 & 0,42 & 0,63 & \\
\hline & Л. Sutan Syahrir & 0,79 & 1,05 & 1,57 & 2,36 & \\
\hline & Л. Sultan Abdurahman & 1,23 & 1,64 & 2,46 & 3,69 & \\
\hline & Л. A Yani & 2,72 & 3,63 & 5,44 & 8,16 & \\
\hline & ת. Veteran & 0,70 & 0,93 & 1,40 & 2,10 & \\
\hline & ת. Pahlawan & 0,34 & 0,45 & 0,68 & 1,02 & \\
\hline & ת. Sultan Hamid II & 3,34 & 4,45 & 6,68 & 10,02 & \\
\hline & ת. 28 Oktober & 3,27 & 4,36 & 6,54 & 9,81 & \\
\hline & Л. Budi Utomo & 4,87 & 6,49 & 9,74 & 14,61 & \\
\hline & Л. Kebangkitan Nasional Dalam & 5,45 & 7,27 & 10,90 & 16,35 & \\
\hline & Total & 22,92 & 30,55 & 45,83 & 68,75 & \\
\hline \multicolumn{3}{|c|}{ Total Waktu $\left(t_{1}+t_{2}+t_{3}\right)$} & \multicolumn{3}{|c|}{145,13} & 2,42 \\
\hline
\end{tabular}


Tabel 8: Total Waktu Tempuh Rute 2

\begin{tabular}{|c|c|c|c|c|c|c|}
\hline \multirow{16}{*}{ Rute 2} & \multirow{3}{*}{ Nama Jalan } & \multirow{3}{*}{$\begin{array}{c}\text { Jarak Jalan } \\
(K m)\end{array}$} & \multicolumn{3}{|c|}{ Waktu (menit/hari) } & Total Waktu \\
\hline & & & \multirow{2}{*}{\begin{tabular}{|c|}
05.00 WIB \\
$\left(t_{1}\right)$
\end{tabular}} & \multirow{2}{*}{$\frac{10.00 \mathrm{WIB}}{\left(\mathrm{t}_{2}\right)}$} & \multirow{2}{*}{$\frac{17.00 \mathrm{WTB}}{\left(\mathrm{t}_{3}\right)}$} & \multirow{2}{*}{ (Jam/hari) } \\
\hline & & & & & & \\
\hline & ת. ProfM Yamin & 0,21 & 0,28 & 0,42 & 0,50 & \\
\hline & ת. Dr Sutomo & 1,18 & 1,58 & 2,36 & 2,84 & \\
\hline & Л. Pangeran Natakusuma & 0,86 & 1,15 & 1,72 & 2,06 & \\
\hline & ת. Alianyang & 0,86 & 1,15 & 1,72 & 2,06 & \\
\hline & ת. Wahid Hasyim & 0,05 & 0,07 & 0,10 & 0,12 & \\
\hline & Л. Johar & 0,43 & 0,57 & 0,86 & 1,03 & \\
\hline & Л. Unip Sumoharjo & 0,66 & 0,87 & 1,31 & 1,57 & \\
\hline & ת. Jendral Sudiman & 0,28 & 0,37 & 0,56 & 0,67 & \\
\hline & Л. Tanjung Pura & 2,05 & 2,73 & 4,09 & 4,91 & \\
\hline & ת. Sultan Hamid II & 3,34 & 4,45 & 6,68 & 8,02 & \\
\hline & Л. 28 Oktober & 3,27 & 4,35 & 6,53 & 7,84 & \\
\hline & ת. Budi Utomo & 4,87 & 6,49 & 9,73 & 11,68 & \\
\hline & Л. Kebangkitan Nasional Dalam & 5,45 & 7,27 & 10,90 & 13,08 & \\
\hline & Total & 23,50 & 31,33 & 46,99 & 56,39 & \\
\hline \multicolumn{3}{|c|}{ Total Waktu $\left(t_{1}+t_{2}+t_{3}\right)$} & \multicolumn{3}{|c|}{134,70} & 2,25 \\
\hline
\end{tabular}

Tabel 9: Total Waktu Tempuh Rute 3

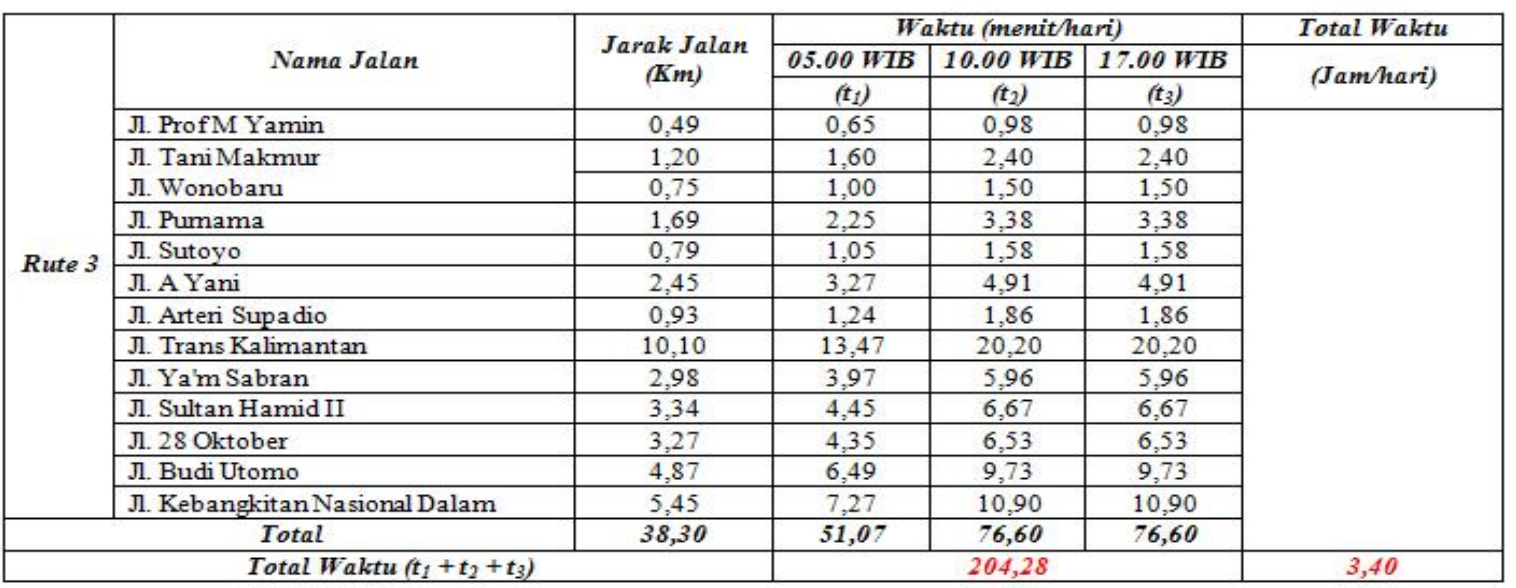

Jadi, dapat disimpulkan dari 3 (tiga) tabel rute diatas hasil waktu validasi survey lapangan yang telah didapatkan sama seperti hasil model yang telah dibuat dengan menggunakan Arcgis yaitu rute 2 (dua) total waktu 2,25 jam/hari.

\section{Kesimpulan}

Dari penelitian yang telah dilaksanakan maka dapat disimpulkan ;

1. Jumlah total volume sampah di TPS Pasar Kemuning adalah sebanyak $58,339 \mathrm{~m}^{3} / \mathrm{hari}$, dengan $14,952 \mathrm{~m}^{3} /$ hari volume bak container dan $43,747 \mathrm{~m}^{3} /$ hari bak dump truck sampah yang ditampung oleh TPS Pasar Kemuning setiap hari.

2. Kurangnya kesadaran masyarakat sekitar yang masih banyak membuang sampah tidak sesuai dengan jam yang telah ditentukan pemerintah. Oleh sebab itu masih banyak sampah yang menumpuk diluar dari tempat penampungan TPS karena terbatasnya jumlah tempat pembuangan sampah yang hanya ada di TPS Pasar Kemuning sehingga TPS Pasar Kemuning menjadi kotor.

3. Jumlah alat angkut/armada untuk mengangkut sampah dari TPS Pasar Kemuning menuju TPA Batu Layang membutuhkan 7 (tujuh) buah alat angkut, antara lain 3 (tiga) buah container dan 4 (empat) buah dump truck untuk mengangkut sampah, dimana pada saat ini untuk alat angkut container TPS Pasar Kemuning hanya memiliki 2 (dua) buah pengangkutan sampah dari TPS ke TPA Batu Layang sehingga 1 (satu) buah container dapat mengangkut 2 (dua) rit/hari dan 1 (satu) buah container mengangkut 1 (satu) rit/hari pada jam operasional pengangkutan sedangkan untuk alat angkut dump truck dibutuhkan 4 (empat) buah dump 
truck, tetapi pada saat ini hanya ada 2 (dua) alat angkut sehingga 2 (dua) buah Dump Truck tersebut mengangkut 2 (dua) rit/hari.

4. Rute yang ditampilkan pada layout ArcGis diperoleh rute 2 (dua) yang menjadi rute terbaik atau rute optimal yang melewati rute pengangkutan TPS Pasar Kemuning sampai TPA Batu Layang dengan jarak tempuh $\pm 24 \mathrm{Km}$ dan waktu 2,25 jam/hari. Seperti pada rute jalan Jl. Prof M Yamin, Jl. Dr Sutomo, Jl. Pangeran Natakusuma, Jl. Alianyang, Jl. Wahid Hasyim, J. Johar, JI. Urip Sumoharjo, Jl. Jendral Sudirman, JI. Tanjung Pura, JI. Sultan Hamid II, JI. 28 Oktober, Jl. Budi Utomo, Jl. Kebangkitan Nasional Dalam.

\section{Ucapan Terima Kasih}

Penulis mengucapkan terima kasih kepada kedua orang tua yang telah memberi dukungan secara moril maupun materil. Penulis juga mengucapkan terima kasih kepada Ibu Sumiyattinah, ST.MT dan Bapak Robby Irsan,ST.M.Si selaku dosen pembimbing dalam penelitian ini. Tidak lupa juga kepada teman-teman angkatan 2008 (SEBVYRUS) Fakultas Teknik UNTAN yang telah membantu pada proses pembuatan skripsi ini.

\section{Referensi}

Alfiandra. 2010. Pengelolaan Persampahan 3R Dikelurahan Ngaliyan Dan Kalipancur Kota Semarang. Tesis. Semarang: Universitas Diponogoro. http://eprints.undip.ac.id/24266/ALFIANDRA.pdf Damanhuri. E. \& Tri. P. 2004. Diktat Kuliah Teknik Lingkungan Pengelolaan Sampah. Departemen Teknik Lingkungan Institut Teknologi Bandung.

Tchobanoglous, G., Teisen H., Eliasen, R, 1977, Solid Wastes, Mc.Graw Hill : Kogakusha, Ltd.

ESRI. 1998. "Spatial Data Warehousing", An ESRI White Paper. 